\title{
Seroprevalence of Human Immunodeficiency Virus, Hepatitis B, Hepatitis C, Syphilis and Co-Infections among Antenatal Women: A Retrospective Case Study at National Hospital Abuja, Federal Capital Territory (FCT), Nigeria
}

\author{
Article by Adedamola Amos Ogundeji \\ PhD (Public Health), Texila American University \\ E-mail: damolaogundeji@gmail.com
}

\begin{abstract}
Objective: The aim of the present study is to determine the seroprevalence of HIV, hepatitis B virus $(H B V)$, hepatitis $C$ virus $(H C V)$, syphilis, and co-infections among antenatal women in National Hospital Abuja, Federal Capital Territory (FCT), Nigeria.

Background: Sexually transmitted infections and human immunodeficiency virus (HIV)/AIDS are a major public health concern owing to both their prevalence and propensity to affect offspring through vertical transmission.

Aim: This study aimed at determining the seroprevalence of HIV, Hepatitis B Virus (HBV), Hepatitis $C$ Virus (HCV), syphilis, and co-infections among antenatal women in National Hospital Abuja, Federal Capital Territory (FCT) Nigeria.

Materials and Methods: A two (2) years retrospective study of antenatal women that attended National Hospital Abuja, Federal Capital Territory (FCT), Nigeria from $1^{\text {st }}$ March, 2013 to $28^{\text {th }}$ February, 2015. A pretested data extraction form was used to obtain data on socio-demographic variables and screening test results from the antenatal records. The analysis was conducted using SPSS version 17 (Chicago, IL, USA).

Results: A total of 3748 antenatal records was used for the study. The seroprevalence of HIV, HCV, HBsAg and syphilis among the pregnant women were $7.9 \%(296 / 3748), 4.7 \%$ (176/3748), $10.6 \%$ ( $397 / 3748)$ and $1.1 \%(41 / 3748)$, respectively. The HIV/HBV, HIV/HCV and HIV/Syphilis co-infection prevalence rates were $0.24 \%(9 / 3748), 0.13 \%(5 / 3748)$ and $0.05 \%(2 / 3748)$ respectively. There was no HBC and HCV co-infection among both HIV positive and negative antenatal women. There was statistically significant difference in $H B V$ and $H C V$ infection between the HIV positive and negative antenatal women.

Conclusion: The prevalence of $H I V, H B V, H C V$, and syphilis is still a challenge in Abuja. Community health education is urgently require to reduce the prevalence of these infections among the most productive and economically viable age bracket. Our study showed that it is very necessary/important for all pregnant women to be requested to test for HBV, HCV alongside the conventional syphilis and HIV infections, in order to prevent vertical transmission to their unborn babies.

Preceptor/location of project: National Hospital Abuja, Federal Capital Territory (FCT), Nigeria.
\end{abstract}

\section{Introduction}

Human immunodeficiency Virus (HIV), Hepatitis B virus (HBV), and Hepatitis C virus (HCV), are the three most common chronic viral infections all over the world ${ }^{1}$. They share similar transmission routes including sexual intercourse, blood-blood contact, mother-to-child transmission and injecting drug usage ${ }^{2}$.

Sub-Saharan Africa, the hardest hit region, is home to more than two-thirds (69\%) of people living with HIV, but only about $12 \%$ of the world's population ${ }^{3}$. Nigeria still has one of the largest HIV prevalence among pregnant women, ranging from as low as $1.6 \%$ in the west, to $8 \%$ in the South-South, $6.5 \%$ in the South-East, and the North-Central region recorded $10 \%{ }^{4}$.Over 2 billion of the world's population have been exposed to HBV and an estimated 387 million of these are now chronically infected with a rate of 10 million new carriers every year ${ }^{5}$. About, $13 \%$ of the carriers will die from the consequences of the HBV infection with an overall annual mortality of about 1 million $^{6}$. The overall prevalence of $\mathrm{HCV}$ in sub-Saharan Africa is $3 \%^{7}$. There are several routes of transmission of HCV but 
direct percutaneous inoculation is the most efficient ${ }^{8}$. In the South-West Nigeria, a higher percentage of those with HCV infection had additional risk factors, especially scarification marks?.

Syphilis is also a systemic disease caused by Treponema pallidium, which can be transmitted by sexual contact, blood transfusion, and vertical transmission ${ }^{10}$.

Mother-to-child transmission of syphilis leads to severe morbidity and mortality including abortion, intrauterine and neonatal death ${ }^{11}$. Congenital syphilis is still a very common occurrence among developing countries, due to non-compliance of women to antenatal care or non-inclusion of syphilis screening as a component in antenatal care ${ }^{12}$.

As a results of the similarity in the routes of transmission, many pregnant women have been exposed to HIV, HBV, HCV, and syphilis infections in different combinations. A study on blood donors showed that prevalence of $\mathrm{HIV}, \mathrm{HBV}, \mathrm{HCV}$, and syphilis were $3.8 \%, 4.7 \%, 0.7 \%$, and $1.3 \%$, respectively ${ }^{13}$. Among the co-infected population, the commonest combinations were HIV/syphilis (38\%) and HIV/HBV $(34 \%)^{13}$. These co-infected population have been categorised with reduced survival, drug associated hepatotoxicity, drug resistance, cross-resistance, and sub-optimal response ${ }^{14}$. Sexually transmitted infections with HIV/AIDS are a major public health concern owing to both their prevalence and propensity to affect offspring through vertical transmission, especially among pregnant women ${ }^{15}$.

Although data on HIV-syphilis co- infection is generally scarce, there is little or no data on the co infections of HIV with HBV, HCV and syphilis especially among pregnant women particularly from Abuja, FCT and its environs where NHA is located. Non-availability of data will cause inability to check and manage the devastating effects of these co infections which will ultimately result in complications of childbirth as well as neonatal infections thus delaying the progression to achieving the MDGs on maternal and child health.

There are worldwide variations in seroprevalence of these infections depending on geographic area, risk groups, and types of exposure involved ${ }^{16}$. Therefore, this study was carried out in order to assess the prevalence of HIV, $\mathrm{HBV}, \mathrm{HCV}$, syphilis, and co-infections among pregnant women receiving care from National Hospital Abuja, Federal Capital Territory (FCT), Nigeria. The rational for choice of this hospital for this study is that it's serve as the final tertiary health care referral centre for the neighbouring states and entire country as a whole due to availability of the state-of-arts and sophisticated modern equipment. The NHA located at the Federal capital city of Nigeria, the seat of power is very unique and best centre for research activities purely because it's attracted patients from the six geo-political zones and will consequently provide a true reflection of Nigeria population research outcome. The outcome will help in formulating intervention plan/policies aimed at reducing the spread of these infections.

\section{Methodology}

\section{Study area and rational for its selection}

The National Hospital Abuja (NHA) is a 350-bed tertiary hospital, located in the Central Business District of the Federal Capital Territory, with state-of-the-art equipment for both clinical and Laboratory settings. This hospital used to serve as the final tertiary health care referral centre for the entire country until recently when some selected teaching hospitals across Nigeria were upgraded to its level in terms of availability of sophisticated modern equipment and adequate manpower with vast experiences in their various disciplines. The hospital currently still serve as epic referral centre for many States around Federal Capital Territory, Abuja. The NHA located at the Federal capital city of Nigeria, the seat of power is very unique and best centre for research activities purely because it's attracted patients from the six geo-political zones and will consequently provide a true reflection of Nigeria expected research outcome. The Medical Microbiology and Parasitology department of the NHA received average of 45 blood samples per week from patients enrolled at the hospital antenatal clinic, which are screened for HIV, HBsAg, HCV and Syphilis (VDRL).

\section{Study design}

This is a retrospective study and so all the data of pregnant women that attended the antenatal clinic of the National Hospital Abuja from $1^{\text {st }}$ March, 2013 to $28^{\text {th }}$ February, 2015 were collated and used for this research. A total of 4986 pregnant women attended the antenatal clinic within that set data collection period. All the antenatal data were completely reviewed and 3748 of them met the inclusion criteria 
while 1238 of them did not. Pretested data extraction form was used to obtain information on the sociodemographic status, parity and screening for HIV, hepatitis B surface antigen (HBsAg), syphilis and $\mathrm{HCV}$ from the antenatal records. The data were extracted by two trained and experience Data Officer who double-checked each other's work to ensure collation of reliable, high quality and accurate data.

\section{Inclusion/exclusion criteria's and ethical review clearance}

All the antenatal data with complete sociodemographic variables, HIV, HBV, HCV, and syphilis screening results were used while incomplete once are excluded from this study. Antenatal women whose mothers were HCV, HBV or HIV carriers were excluded from the study. This study was approved by the Head of Microbiology Department and Ethics Committee of the National Hospital Abuja.

\section{Test kits used for the study}

Antibodies to both HCV and Hepatitis B surface antigen were screened with Clinotech diagnostic enzyme-linked immunosorbent (ELISA) test kits (Clinotech Laboratories, USA with the test specificity of $99.7 \%$ and sensitivity of $100 \%$ for both HbsAg and HCV test kits. Syphilis was screened using Veneral Disease Research Laboratory (Clinotech Biotech Inc., California; with test sensitivity of 100\%, specificity 99.7\%). Antibodies to T. pallidum were confirmed with T. pallidum hemagglutination test. Antibodies to HIV-1 and -2 were screened with Abott Determine and Immunocomb (Alere Medical Company, Limited, Japan; sensitivity 100\%, specificity 99.5\%). All reactive samples were confirmed using ELISA.

\section{Sample collection}

Five millilitres $(5 \mathrm{ml})$ of venous blood was collected from each patient using plain vacutainer tubes (Sterile Separator Tube-SST). Samples were allowed to clot and centrifuged at 1000xg for 10minutes. Serum from the samples tubes were separated into sterile $2 \mathrm{ml}$ cryovial containers and stored at $-20 \mathrm{oC}$ until ready for use.

\section{HIV serology}

HIV screening was carried out using the rapid diagnostics test kits, by adopting serial National Testing algorithm ${ }^{16}$. Samples were first tested using Determine HIV kit (Alere Medical Co., Japan). All positive samples were further tested using Unigold HIV kit (Trinity Biotech Plc, Ireland) and positive results were presumptively considered as positive. Unigold test kit is use as second line (confirmatory) and when it is negative, then Stat-pak HIV kit (a tie breaker) by (CHEMBIO USA) was then used. All test kits procedures were done according to their respective manufacturers' instruction. All reactive samples were confirmed using ELISA.

\section{Syphilis IgM serology}

Screening for syphilis was carried out using Enzyme Immunoassay (ELISA) technique to determine specific IgM antibodies to Treponema palladium in human serum and plasma (DIA.PRO Diagnostic Bio-probes, Milano-Italy). The samples were tested following the manufacturer instructions and was read with a spectrophotometer (name and country of manufacture) at dual wave lengths (450 and $620 \mathrm{~nm})$.

\section{Hepatitis B and C serology}

Hepatitis B virus infection was detected using the commercially available rapid test strip which is a qualitative lateral flow immunoassay kit for testing HBsAg in serum and plasma. Similarly, Hepatitis $\mathrm{C}$ virus infection was tested using the commercially available rapid test strip which is a qualitative, membrane (coated with recombinant $\mathrm{HCV}$ antigen on the test line region of the strip) based immunoassay for the detection of HCV antibodies in serum and plasma. Both HBsAg and HCV test kits were manufacture by Acon Laboratories, Inc., San Diego, USA. All reactive samples were respectively confirmed using ELISA. 
DOI: $10.21522 / \mathrm{TIJPH} .2013 .06 .02$. Art001

ISSN: $2520-3134$

\section{Statistical analysis}

Statistical analysis was achieved using SPSS version 17 (Chicago, IL, USA). Chi-square analysis was used for discrete variables and $P<0.05$ were considered as statistically significant. The results were presented in tables and simple percentages.

\section{Results}

Of 3748 antenatal women, 296 were HIV positive giving a seroprevalence rate of $7.9 \%$ (296/3748), 42 were $\mathrm{HBV}$ positive resulting in an HBV seroprevalence of $10.6 \%$ (397/3748), and 32 of them were positive to HCV antibodies with a seroprevalence rate of $4.7 \%$ (176/3748) [Table 1]. Forty one of the pregnant women was Treponema palladium hemoagglutination assay positive with seroprevalence rate of $1.1 \%(41 / 3748)$.

Table 1. Screening pattern of the antenatal women

\begin{tabular}{|l|l|l|}
\hline $\begin{array}{l}\text { Screening Pattern of } \\
\text { women }\end{array}$ & $\begin{array}{l}\text { Frequency } \\
(\mathbf{n = 3 7 4 8})\end{array}$ & Percentage \\
\hline HIV Screening Pattern & 296 & 7.9 \\
\hline Positive & 3452 & 92.1 \\
\hline Negative & 397 & 10.6 \\
\hline HBsAg Screening Pattern & 89.4 \\
\hline Positive & 3351 \\
\hline Negative & 176 & 4.7 \\
\hline HCV Screening Pattern & 3572 & 95.3 \\
\hline Positive & 1.1 \\
\hline Negative & 41 & 98.9 \\
\hline Syphilis Screening Pattern & 3707 \\
\hline Positive & $\begin{array}{l}\text { Negative } \\
\text { HCV: Hepatitis C Virus, HIV: Human Immunodeficiency Virus, } \\
\text { HBsAg: Hepatitis B Surface Antigen }\end{array}$ \\
\hline
\end{tabular}

Nine (9) out of 3748 women were both HIV and HBV positive with co-prevalent rate of $0.24 \%$ [Table 2]. As was shown by the Chi-square values in [Table 2], there was statistically significant difference in HBV infection between the HIV positive and negative antenatal women. Five (5) women were both HIV and HCV positive with a seroprevalent rate of $0.13 \%$ (5/3748). Similarly in [Table 2], there was no statistically significant difference in HCV infection between the HIV positive and negative women. Again, only two (2) pregnant women that was T. pallidium hemoagglutination test positive was also HIV positive with co-prevalent rate of $0.05 \%$ (2/3748). There was no HBV, HCV, and syphilis co-infection in both HIV positive and negative antenatal women in this study.

Table 2. HIV, HBV, HCV and Syphilis co-infection

\begin{tabular}{|c|c|c|c|}
\hline & \multicolumn{2}{|l|}{ HBV } & \multirow[t]{2}{*}{ TOTAL } \\
\hline & POSITIVE & NEGATIVE & \\
\hline \multicolumn{4}{|l|}{ HIV } \\
\hline Positive & 9 & 287 & 296 \\
\hline Negative & 388 & 3064 & 3452 \\
\hline Total & 397 & 3351 & 3748 \\
\hline \multicolumn{4}{|c|}{$\chi^{2}=19.353, \mathrm{df}=1, P<0.05$ (Significant different) } \\
\hline \multicolumn{4}{|l|}{ HCV } \\
\hline \multicolumn{4}{|l|}{ HIV } \\
\hline Positive & 5 & 291 & 296 \\
\hline Negative & 171 & 3281 & 3452 \\
\hline Total & 176 & 3572 & 3748 \\
\hline
\end{tabular}




\begin{tabular}{|c|c|c|c|}
\hline \multicolumn{4}{|c|}{$\chi^{2}=6.492, \mathrm{df}=1, P<0.05$ (Significant different) } \\
\hline \multicolumn{4}{|l|}{ Syphilis } \\
\hline \multicolumn{4}{|l|}{ HIV } \\
\hline Positive & 2 & 294 & 296 \\
\hline Negative & 39 & 3413 & 3452 \\
\hline Total & 41 & 3707 & 3748 \\
\hline
\end{tabular}

The most predominant age group of the women was 21-30 years 50.4\% (1889/3748). The mean (SD) for age was 30.1 (2.1) years [Table 3]. One thousand five hundred and eighty-six 42.3\%(1586/3748) of the women were public/civil servants followed by the unemployed group 26.1\% (978/3748). [Table 3 ] also shows that most of the antenatal women $41.7 \%$ (1563/3748) were multiparous.

Table 3. Sociodemographic variables among the antenatal women

\begin{tabular}{|l|l|l|}
\begin{tabular}{|l|l|} 
Sociodemographic \\
characteristics
\end{tabular} & $\begin{array}{l}\text { Frequency } \\
(\mathbf{n = 3 7 4 8})\end{array}$ & $\begin{array}{l}\text { Percentage } \\
(\%)\end{array}$ \\
\hline Age (years) & 79 & 2.1 \\
\hline $11-20$ & 1889 & 50.4 \\
\hline $21-30$ & 1638 & 43.7 \\
\hline $31-40$ & 142 & 3.8 \\
\hline $41-50$ & 1586 & 42.3 \\
\hline Occupation & 978 & 26.1 \\
\hline Public/Civil Servants & 506 & 13.5 \\
\hline Unemployed group & 457 & 12.2 \\
\hline Trading & \multicolumn{2}{|l|}{} \\
\hline $\begin{array}{l}\text { Professionals (Engineers, Lawyer, } \\
\text { Doctors, Accountants etc.) }\end{array}$ & 221 & 5.9 \\
\hline Artisans & \multicolumn{2}{|l|}{} \\
\hline Parity Distribution & 1102 & 29.4 \\
\hline 0 & 810 & 21.6 \\
\hline 1 & 1563 & 41.7 \\
\hline $2-4$ & 273 & 7.3 \\
\hline$>5$ & \multicolumn{2}{|l|}{} \\
\hline
\end{tabular}

[Table 4] revealed that the unemployed group, public servants of the antenatal women and the Artisans constitute the bulk of the women that were seropositive to HIV, HBV, and HCV anti-bodies.

Table 4. Occupational distribution of the women HIV, HBsAg and HCV infection

\begin{tabular}{|c|c|c|c|c|c|c|}
\hline \multirow{2}{*}{ Occupation } & \multicolumn{2}{|l|}{ HIV } & \multicolumn{2}{|l|}{ HBsAg } & \multicolumn{2}{|l|}{ HCV } \\
\hline & Positive & Negative & Positive & Negative & Positive & Negative \\
\hline $\begin{array}{l}\text { Public/Civil } \\
\text { Servants }\end{array}$ & $71(4.5 \%)$ & $\begin{array}{l}1515 \\
(95.5 \%)\end{array}$ & $83(5.2 \%)$ & $\begin{array}{l}1503 \\
(94.8 \%)\end{array}$ & $51(3.2 \%)$ & $1535(96.8 \%)$ \\
\hline Unem & $\begin{array}{l}121 \\
(12.4 \%)\end{array}$ & $856(87.6 \%)$ & $\begin{array}{l}123 \\
(12.6 \%)\end{array}$ & $855(87.4 \%)$ & $55(5.6 \%)$ & $923(94.4)$ \\
\hline Trading & $43(8.5 \%)$ & $463(91.5 \%)$ & $68(13.4 \%)$ & $438(86.6 \%)$ & $27(5.3 \%)$ & $479(94.7 \%)$ \\
\hline Professionals & $9(2.0 \%)$ & $448(98.0 \%)$ & $40(8.8 \%)$ & $417(91.2 \%)$ & $5(1.1 \%)$ & $452(98.9 \%)$ \\
\hline Artisan & $52(23.5 \%)$ & $169(76.5 \%)$ & $83(37.6 \%)$ & $138(62.4 \%)$ & $38(17.2 \%)$ & $183(82.8 \%)$ \\
\hline Total & $296(7.9 \%)$ & $\begin{array}{l}3452 \\
(92.1 \%) \\
\end{array}$ & $\begin{array}{l}397 \\
(10.6 \%)\end{array}$ & $\begin{array}{l}3351 \\
(89.4 \%)\end{array}$ & $176(4.7 \%)$ & $3572(95.3 \%)$ \\
\hline
\end{tabular}


DOI: $10.21522 / \mathrm{TIJPH} .2013 .06 .02$. Art001

ISSN: $2520-3134$

\section{Discussion}

The seroprevelance of HIV, HBV, HCV and Syphilis infections is well recognized worldwide but has been reported to be more common in developing countries in Africa and Asia ${ }^{11}$. This study was carried out to assess the seroprevalence of HIV, HBV, HCV and Syphilis co infections among pregnant women attending National Hospital Abuja, Federal Capital Territory, and North central Nigeria. The study demonstrated a high prevalence of HIV (7.9\%) and HBV (10.6\%) and a low prevalence of HCV (4.7\%) and Syphilis (1.1\%).

The findings where the majority of pregnant women tested were between the age bracket of $15-35$ is also in agreement with an earlier report by Ajayi et al 2012 and national survey (FMOH 2002) that the majority of the pregnant women tested (95\%) were between the ages of 15-35 years.

The overall seroprevalence of HIV, 7.9\% among antenatal women in Abuja and its environs recorded in this study is higher than the national HIV prevalence of $4.6 \%$ among pregnant women. It is also in agreement, when compared with the $7.8 \%$ reported in Minna ${ }^{16}$.

In North-West Ethiopia, a seroprevalence of $9.6 \%$ for HIV-1 was observed among pregnant women receiving antenatal services at the University of Gondar Teaching Hospital ${ }^{14}$. The seroprevalence in this study is lower than the $26 \%$ seroprevalence reported in Swaziland ${ }^{17}$. The seroprevalence of HIV, $7.9 \%$ in this study could be due to increased level of awareness among antenatal women in Abuja and environs on the Prevention of Mother to Child Transmission (PMTCT) of HIV/AIDS as well as the functional PMTCT program at National Hospital, Abuja thereby attracting more HIV-positive pregnant women to book at the facility for antenatal care.

The seroprevalence of HBV 10.6\%, among the women is higher than previous reports from Nigeria; $8.2 \%$ in Yola $^{18}$, and 5\% in Niger Delta ${ }^{19}$. It is similar to $3.7 \%$ reported in Jimma, Ethiopia ${ }^{20}$. Higher prevalence was recorded among pregnant Sudanese 5\% $\%^{21}$, and India women $3.07 \%^{22}$.

However, cross-study comparisons may be misleading because of the kits used for different assays. The use of polymerase chain reaction (PCR) and ELISA technique assays in other studies have been shown to be more sensitive than the serological methods used in this study ${ }^{23}$. In addition, the differences in the sociodemographic characteristics of the women should be taken into consideration in such comparisons.

The HCV antibody prevalence among the women in the study was $4.7 \%$. This is in agreement with the overall seroprevalence of HCV in sub-Saharan Africa 3\% $\%^{7}$. It is however, higher than the result from Niger Delta, Nigeria $0.5 \%^{20}$, Iran $0.98 \%^{24}$, and Sudan $<1 \%{ }^{22}$. These variations may be related to the differences in the modes of transmission, which is influenced by socio-cultural practices and environmental factors ${ }^{20}$. In a tertiary Medical Centre in South-West Nigeria where over $90.8 \%$ of the women had scarification marks, a seroprevalence of $9.2 \%$ was reported ${ }^{9}$. The differences have also been attributed to the choice of serological tests to determine HCV prevalence especially in developing countries where intercurrent infections contribute to false-positive enzyme immunoassay results ${ }^{25}$.

From this study, the seroprevalence of syphilis among antenatal attendees in Abuja is $1.1 \%$. The seroprevalence is higher than the national average for syphilis in pregnant Nigeria women, $0.3 \%{ }^{26}$. However, a higher prevalence of $10 \%$ was reported among pregnant women in Oshogbo, south western Nigeria $^{27}$. In agreement with this study, the seroprevalence of syphilis among antenatal women in Gondar, Ethiopia, was $1 \%{ }^{10}$. The variation is seroprevalence could be attributed to the differences in sexual practices and behaviour. Late seeking of effective medical treatment for sexually transmitted infections among the largely literate urban antenatal women may explain the elevation. The high prevalence has also been attributed to over-the-counter abuse of antibiotics for minor complaints leading to drug resistance ${ }^{10}$.

From this study, HIV and HBV co-infection prevalent rate of $0.24 \%$ was recorded. This is lower than $0.7 \%$ reported in Anambra state ${ }^{17}$. Also, in this study, $0.13 \%$ and $0.05 \%$ of the antenatal women were positive for HIV-HCV and HIV-Syphilis respectively. Again, only $0.05 \%$ of the women that was positive for syphilis was also HIV positive and whether syphilis predisposed them to HIV and vice versa could not be ascertained by this study. There was no HBV and HCV co-infection in both HIV positive and negative women and this supported the study in Rwanda and Uganda ${ }^{28}$, but varied with the results from Malekan City, Iran ${ }^{25}$. The difference in HBV and HCV infection in both HIV-positive and negative antenatal women in National Hospital Abuja was statistically significant $(\mathrm{p}<0.05)$. The 
absence of HCV and HBV infections in both HIV negative and positive women may be due to the absence of such risk factors as injection drug use commonly seen in the West and scarification marks that are not common in Abuja and its environs, where the study was conducted.

The age group of 21-40 years had the predominant HIV, HBV, and HCV prevalence and this supported the studies in North-West Ethiopia ${ }^{10}$. This calls for concerted efforts aimed at preventive measures to reduce risky lifestyle practices among the most productive and economically viable age bracket $^{13}$.

The unemployed group and artisans similarly had the highest seroprevalence of HIV, HBV and HCV. This study generally recorded high prevalence of HIV (23.5\%), HBV (37.6\%) and HCV (17.2\%) among artisans population as against very low prevalence of HIV (2.0\%), HBV (8.8\%) and HCV (1.1\%) among professionals population that participated in the study. This study shows a very significant different in the seroprevalence of HIV, HBV and HCV among artisan/unemployed and professionals respectively (i.e. poorer society and upper class). A similar observation in Anambra State, Nigeria ${ }^{29}$ showed that the occupation of the antenatal women influenced the infection of the women. Low socioeconomic factor initiates multiple sexual partnership, unprotected sex, and predisposes to sexually transmitted infections ${ }^{30}$

This study has a number of limitations. This is a retrospective study conducted in an urban area based hospital and consisted of only pregnant women who were able to access hospital; for this reason, the seroprevalence reported here maybe a lower estimate of the true prevalence among pregnant women in Abuja, FCT, Nigeria. The rate might be higher in individuals who had a lower socioeconomic status such that they could not even reach a hospital from the rural area. No data is available for such risk factors as residence and place of birth. The population size is relatively small when compare to about 170million Nigerian population, and it will not be possible to generalize the outcome of the study.

\section{Conclusion}

Human immunodeficiency virus, $\mathrm{HBV}$, and $\mathrm{HCV}$ infection is a major global health problem necessitating a high priority in their prevention and control. There is a need for effective health education on behavioral change as well as the inclusion of HBV immunization for women of reproductive age to reduce the risk of spread to neonates through mother to child transmission. The significantly high seroprevalence of HIV, HBV and HCV recorded in this study especially among artisans/unemployed should the vigorously address by way of education and enlightenment campaign targeted among this population in order to reduce this scourge to barest minimum. The low seroprevalence of syphilis observed in this study should not engender complacency in view of the deleterious effect of untreated maternal infection on pregnancy outcome and spread of HIV.

\section{Acknowledgement}

Special appreciation goes to the management of National Hospital Abuja, Head of Department (HOD), the Chief Medical Laboratory Scientist (CMLS) and the entire staffs of Department of Medical Microbiology and Parasitology for granting me access to the data for this study.

\section{References}

[1].Awole M, Gebre-Selassie S. Sero prevalence of HBsAg and its risk factors among pregnant women in Jimma, South west Ethiopia. Ethiop J Health Dev 2005; 19:45-50.

[2].Awang EW, Cheung R. Global epidemiology of hepatitis B virus (HBV) infection. N Am J Med Sci 2011; $4: 7-13$

[3].Bahaf F, Tanom A, Montazam H, Sany AA. Seroprevalence of hepatitis C, hepatitis B and HIV and coinfections among pregnant women: A retrospective study in 2006 Malekan City, Iran. Res J Med Sci 2007; 1:13841.

[4].Buseri F, Seiyaboh E, Jeremiah Z. Surveying infections among pregnant women in the Niger Delta, Nigeria. J Glob Infect Dis 2010; 2:203-11.

[5].Drosten C, Nippraschk T, Manegold C, Meisel H, Brixner V, Roth WK, et al. Prevalence of hepatitis B virus DNA in anti-HBc-positive/HBsAg-negative sera correlates with HCV but not HIV serostatus. J Clin Virol 2004; 29:59-68. 
DOI: $10.21522 / \mathrm{TIJPH} .2013 .06 .02$. Art001

ISSN: $2520-3134$

[6].Elsheikh RM, Daak AA, Elsheikh MA, Karsany MS, Adam I. Hepatitis B virus and hepatitis C virus in pregnant Sudanese women. Virol J 2007; 4:104.

[7].FMOH, (2010) Department of public health, National AIDS/STI control Programme ANC Sentinel Survey Nigeria, 2010; Pg 9-10.

[8].Federal Ministry of Health, Nigeria (FMOH). Technical Report on 2003 National HIV/Syphilis Sentinel Survey among Women Attending Antenatal Clinics in Nigeria. Abuja: Nigeria Federal Ministry of Health; 2004. [9].Gonçales FL Jr, Pereira JS, Da Silva C, Thomaz GR, Pavan MH, Fais VC, et al. Hepatitis B virus DNA in sera of blood donors and of patients infected with hepatitis $\mathrm{C}$ virus and human immunodeficiency virus. Clin Diagn Lab Immunol 2003; 10:718-20.

[10]. Hou J, Liu Z, Gu F. Epidemiology and prevention of hepatitis B virus infection. Int J Med Sci 2005; 2:50-7. [11]. Kebede E, Chamiso B. Prevalence of syphilis in pregnancy in Addis Ababa. East Afr Med J 2000; 77:2126.

[12]. Koziel M, Peters M: Viral hepatitis in HIV infection. N Engl J Med 2007, 356:1445-1454.Saravanan S, Velu $\mathrm{V}$, Kumarasamy N, Nandakumar S, Murugavel K, et al.: Coinfection of hepatitis B and hepatitis C virus in HIVinfected patients in South India. World J Gastroenterol 2007, 13:5015-5020.

[13]. Khakhkhar VM, Bhura PJ, Bhuva SP, Patel CP, Cholera MS. Sero prevalence of hepatitis B amongst pregnant women attending the antenatal clinic of a tertiary care hospital, Jamnagar (Gujarat). Natl J Med Res 2012; 2:362-5.

[14]. Madhava V, Burgess C, Drucker E. Epidemiology of chronic hepatitis C virus infection in sub-Saharan Africa. Lancet Infect Dis 2002; 2:293-302.

[15]. Mulu A, Kassu A, Tessema B, Yismaw G, Tiruneh M, Moges F, et al. Seroprevalence of syphilis and HIV1 during pregnancy in a teaching hospital in northwest Ethiopia. Jpn J Infect Dis 2007; 60:193-5.

[16]. Nelson, B. Mathers, B. Cowie, et al., "The epidemiology of viral hepatitis among people who inject drugs: results of global systematic reviews,” The Lancet, vol. 378, no. 9791, pp. 571-583, 2011.

[17]. Ndams IS, Joshua IA, Luka SA, Sadiq HO, Ayodele SB. Human immunodeficiency virus seroprevalence among pregnant women in Minna, Nigeria. Ann Niger Med 2010; 4:14-7.

[18]. Osotimehin B. Director General, National Action Committee for the Control of AIDS (NACA), Federal Ministry of Health, Nigeria. NACA Bulletin; July 2008.

[19]. Ogunro PS, Adekanle DA, Fadero FF, Ogungbamigbe TO, Oninla SO. Prevalence of anti-hepatitis C virus antibodies in pregnant women and their offspring in a tertiary hospital in Southwestern Nigeria. J Infect Dev Ctries $20071 ; 1: 333-6$.

[20]. Olokoba AB, Salawu FK, Danburam A, Olokoba LB, Midala JK, Badung LH, et al. Hepatitis B virus infection amongst pregnant women in North-eastern Nigeria-A call for action. Niger J Clin Pract 2011; 14:10-3. [21]. Ojo DA, Oyetunji IA. Sero prevalence of syphilis among pregnant women in Osogbo in Southwestern Nigeria. Asset Ser B 2007; 6:61-5.

[22]. Pirillo MF, Bassani L, Germinario EA, Mancini MG, Vyankandondera J, Okong P, et al. Seroprevalence of hepatitis B and C viruses among HIV-infected pregnant women in Uganda and Rwanda. J Med Virol 2007; 79:1797-801.

[23]. Population Reference Bureau. World Population Data Sheet, 2011. Available from: http://www.prb.org//publications/datasheets/2011/world-population-data-Sheet.aspx. [Last assessed on 2013 Sep $02]$.

[24]. Pineda JA, Romero-Gómez M, Díaz-García F, Girón-González JA, Montero JL, Torre-Cisneros J, et al. HIV coinfection shortens the survival of patients with hepatitis $\mathrm{C}$ virus-related decompensated cirrhosis. Hepatology 2005; 41:779-89.

[25]. Raghuraman S, Subramaniam T, Daniel D, Sridharan G, Abraham P. Occurrence of false positives during testing for antibodies to hepatitis C virus among volunteer blood donors in India. J Clin Microbiol 2003; 41:178890.

[26]. Schmid, G., (2004) Bulletin of World Health Organization. 82(6): 402-9.

[27]. Tessema B, Yismaw G, Kassu A, Amsalu A, Mulu A, Emmrich F, et al. Seroprevalence of HIV, HBV, HCV and syphilis infections among blood donors at Gondar University Teaching Hospital, Northwest Ethiopia: Declining trends over a period of five years. BMC Infect Dis 2010; 10:111.

[28]. UNAIDS. 2008 Report on Global AIDS Epidemic. Geneva, Switzerland: UNAIDS; 2008.

[29]. WHO - World Health Organization (2010) HIV/AIDS epidemic update Available from: aids.gov.br. 